\title{
Effects of boron and hydrogen doping on the enhancement of photoresponsivity and photoluminescence of $\mathrm{BaSi}_{2}$ epitaxial films
}

\author{
Louise Benincasa ${ }^{1,2}$, Zhihao $\mathrm{Xu}^{1}$, Tianguo Deng ${ }^{1}$, Takuma Sato ${ }^{1,2}$, Kaoru Toko ${ }^{1}$, and \\ Takashi Suemasu ${ }^{1}$ \\ ${ }^{1}$ University of Tsukuba, Tsukuba, Ibaraki 305-8577, Japan \\ ${ }^{2}$ University of Grenoble-Alpes, 38400 Saint-Martin-d'Hères, France
}

\begin{abstract}
$\mathrm{BaSi}_{2}$ is an emerging material for solar cell applications. We investigate the defect properties of $0.5-\mu \mathrm{m}$-thick $\mathrm{BaSi}_{2}$ films by photoresponse and photoluminescence (PL) measurements. The photoresponsivity of $\mathrm{BaSi}_{2}$ films measured under a bias voltage of 0.3 $\mathrm{V}$ applied between the front-surface and rear-surface electrodes at room temperature was enhanced by doping B atoms of the order of $10^{18} \mathrm{~cm}^{-3}$. Much further enhancement was achieved after atomic $\mathrm{H}$ supply for $5 \mathrm{~min}$ by a radio-frequency plasma gun. These results suggest that the doping of $\mathrm{B}$ and $\mathrm{H}$ atoms is an effective means to passivate the defects in $\mathrm{BaSi}_{2}$ films. PL measurements at 8-9 K highlighted the existence of localized states within the bandgap. Measured PL spectra were decomposed into two or four Gaussian curves. The enhancement of photoresponsivity was ascribed to the decrease of deep defect levels.
\end{abstract}

E-mail: suemasu@bk.tsukuba.ac.jp, louise-benincasa@orange.fr 


\section{Introduction}

Indirect bandgap semiconductor barium disilicide $\left(\mathrm{BaSi}_{2}\right)$ is a new alternative for next generation solar cell applications. The unit cell of $\mathrm{BaSi}_{2}$ contains eight barium atoms $(\mathrm{Ba})$ and 16 silicon atoms ( $\mathrm{Si})$ as shown in Fig. 1. ${ }^{1,2}$ There are two crystallographically inequivalent sites for $\mathrm{Ba}$ and three inequivalent sites for $\mathrm{Si}$. $\mathrm{BaSi}_{2}$ can be grown epitaxially on both $\mathrm{Si}(111)$ and $\mathrm{Si}(001)$ substrates with its $a$-axis normal to the substrate surface..$^{3-5} \mathrm{It}$ thus shows great potential in solar cell applications. ${ }^{6} \mathrm{BaSi}_{2}$ has attractive features such as a suitable band gap $\left(E_{\mathrm{g}}=1.3 \mathrm{eV}\right)$ for a single-junction solar cell, high absorption coefficients exceeding those of CIGS, ${ }^{7-10}$ a long minority-carrier lifetime $(\tau \sim 10 \mu \mathrm{s}),{ }^{11}$ and a large minority-carrier diffusion length $(L \sim 10 \mu \mathrm{m})$ due to inactive grain boundaries. ${ }^{12-14}$ Recently, with the help of a-Si passivation layers, ${ }^{15,16}$ we achieved an conversion efficiency approaching $10 \%$ in $\mathrm{p}-\mathrm{BaSi}_{2} / \mathrm{n}-\mathrm{Si}$ heterojunction solar cells, ${ }^{17-19}$ and demonstrated the operation of $\mathrm{BaSi}_{2}$ homojunction solar cells. ${ }^{20}$ We are now focusing on further improvement of optical properties of $\mathrm{BaSi}_{2}$ films. Undoped-BaSi2 contains point defects which induce localized states within the bandgap. The presence of defects in $\mathrm{BaSi} 2$ films and polycrystalline $\mathrm{BaSi}_{2}$ bulks has been examined by photoluminescence (PL), ${ }^{21,22}$ deep-level transient spectroscopy, ${ }^{23,24}$ and electron paramagnetic resonance. ${ }^{25}$ Carrier type, carrier concentration, and photoresponsivity of $\mathrm{BaSi}_{2}$ films are so sensitive to a Ba-to-Si deposition rate ratio $\left(R_{\mathrm{Ba}} / R_{\mathrm{Si}}\right)$ during molecular beam epitaxy $(\mathrm{MBE})$ of $\mathrm{BaSi}_{2}$ films. ${ }^{26}$ This result suggests that the type of defects changes depending on $R_{\mathrm{Ba}} / R_{\mathrm{Si}}$. According to first-principle calculation, ${ }^{27} \mathrm{Si}$ vacancies $\left(\mathrm{V}_{\mathrm{Si}}\right)$, wherein $\mathrm{Si}(3), \mathrm{Si}(4)$, or $\mathrm{Si}(5)$ atom in Fig. 1 is missing, are most likely to occur among point defects in $\mathrm{BaSi}_{2}$ from the viewpoint of formation energy. Our previous research shows that defects in undoped $\mathrm{BaSi}_{2}$ films are passivated by atomic hydrogen $(\mathrm{H}) .{ }^{28,29}$ The photoresponsivity of $\mathrm{BaSi}_{2}$ films is enhanced markedly by supplying atomic $\mathrm{H}$ after the growth of $\mathrm{BaSi}_{2}$ films for 15 min thanks to the improvement of carrier lifetime, which was proved by microwave-detected photodunctivity measurement. $^{29}$

In this study, we investigate the effect of atomic $\mathrm{H}$ supply on boron(B)-doped $\mathrm{BaSi} 2$ films by evaluating their photoresponse and PL spectra. The basic structure of a solar cell is a pn junction. Therefore, the formation of high-quality $\mathrm{p}$-BaSi2 films is of great importance. $\mathrm{B}$ is a p-type impurity for $\mathrm{BaSi}_{2} .{ }^{30,31}$ The valence band maximum of $\mathrm{BaSi}_{2}$ is mainly composed of Si p states. ${ }^{8,10}$ Thus the replacement of some of $\mathrm{Si}$ atoms in $\mathrm{BaSi}_{2}$ with $\mathrm{B}$ decreases the valence electron concentration, giving rise to $\mathrm{p}-\mathrm{BaSi}_{2}$. We thereby anticipate that doped $\mathrm{B}$ atoms may fill some of $\mathrm{V}_{\mathrm{Si}}$ in $\mathrm{BaSi}_{2}$. Photoresponsivity is used as a 
measure to investigate the optical properties of $\mathrm{BaSi}_{2}$ films because it is sensitive to a carrier lifetime, ${ }^{32}$ meaning that small photoresponsivity indicates that the $\mathrm{BaSi}_{2}$ films are defective. PL offers a nondestructive and sensitive tool for defect studies in solar cell materials such as $\mathrm{Si}^{33-35}$ and provides information about the presence of localized states within the band gap. In this way, we have a better understanding about the origin of these defects and find a way to suppress or reduce them.

\section{Experimental methods}

An ultrahigh vacuum MBE system equipped with a standard Knudsen cell (K-cell) for Ba and a high-temperature K-cell for $\mathrm{B}$, an electron-beam gun for $\mathrm{Si}$ was used. For generating atomic $\mathrm{H}$, a radiofrequency (RF) plasma generator were used. First, we deposited a 3 nm-thick $\mathrm{BaSi}_{2}$ template layer on an $\mathrm{n}-\mathrm{Si}(111)$ substrate by reactive deposition epitaxy (RDE). ${ }^{5}$ In RDE, Ba atoms were deposited on heated Si substrates to form a few nm-thick $\mathrm{BaSi}_{2}$ epitaxial layers under high vacuum, commonly $10^{-7} \mathrm{~Pa}$ at $500{ }^{\circ} \mathrm{C}$. These layers work as a seed crystal to control the crystal orientation of $\mathrm{BaSi}_{2}$ for $\mathrm{BaSi}_{2}$ overlayers. Then, to form a 0.5 - $\mu$ m-thick B-doped BaSi2 epitaxial film, we co-deposited $\mathrm{Ba}, \mathrm{Si}$, and $\mathrm{B}$ by $\mathrm{MBE}$ at $580{ }^{\circ} \mathrm{C}$. We confirmed epitaxial growth was confirmed by reflection high-energy electron diffraction and x-ray diffraction measurement. The temperature of $\mathrm{B}\left(T_{\mathrm{B}}\right)$ was chosen at $1100{ }^{\circ} \mathrm{C}$ or $1230{ }^{\circ} \mathrm{C}$, denoted as "low B-doped" and "high B-doped", respectively, hereafter. The hole concentration $(p)$ of these films is approximately $1 \times 10^{17}$ and $4 \times 10^{18}$ $\mathrm{cm}^{-3}$, respectively, at room temperature (RT). ${ }^{36}$ The B concentration measured by secondary ion mass spectrometry of these samples were approximately $3 \times 10^{16} \mathrm{~cm}^{-3}$ and 3 $\times 10^{18} \mathrm{~cm}^{-3}$, respectively. ${ }^{36}$ We set the $R_{\mathrm{Ba}} / R_{\mathrm{Si}}$ at 2.2 , which is the optimum condition when $\mathrm{BaSi}_{2}$ films were grown at $580{ }^{\circ} \mathrm{C} .{ }^{26}$ For comparison, we also formed a 0.5 - $\mu \mathrm{m}$-thick undoped $\mathrm{BaSi}_{2}$ films. Atomic $\mathrm{H}$ produced by an RF plasma gun was supplied at $580{ }^{\circ} \mathrm{C}$ for several supply durations $\left(t_{\mathrm{H}}\right)$ in the range 0-15 min. Finally, a 3-nm thick a-Si layer was deposited on the $\mathrm{BaSi}_{2}$ thin film at $180{ }^{\circ} \mathrm{C}$. According to our previous work, ${ }^{15,16}$ the a-Si capping layer suppresses the surface oxidation and behaves as a surface passivation layer. Finally, we sputtered 80-nm thick indium-tin-oxide (ITO) electrodes of $1 \mathrm{~mm}$ in diameter on the front surface and 150-nm-thick Al electrodes on the back surface of the Si substrate for the photoresponse measurements. We used two kinds of $\operatorname{Si}(111)$ substrates with different resistivities $(\rho)$, that is $\rho=0.01 \Omega \mathrm{cm}$ or $\rho>1000 \Omega \mathrm{cm}$. For photoresponse measurement, low- $\rho \mathrm{Si}$ substrates were employed to make the contribution of photogenerated carriers in the Si substrate negligibly small. Sample preparation details are 
summarized in Table I.

Photoresponse spectra were measured at RT using a lock-in technique with a xenon lamp $(150 \mathrm{~W})$ and a $25 \mathrm{~cm}$ focal length single monochromator (Bunko Keiki SM-1700A and RU-60N). The chopping frequency was set at $77 \mathrm{~Hz}$. To extract photogenerated electrons in $\mathrm{BaSi}_{2}$ films to the front-surface ITO electrode, a bias voltage of $0.3 \mathrm{~V}$ was applied to the front surface ITO electrode with respect to the rear Al electrode. The light intensity was calibrated using a pyroelectric sensor (Melles Griot 13PEM001/J). PL measurements were conducted at around $8 \mathrm{~K}$ by exciting the samples from the front-side ( $\mathrm{BaSi}_{2}$ side) and the back-side (Si side). The excitation wavelength was $442 \mathrm{~nm}$ or $532 \mathrm{~nm}$ and a liquid nitrogen cooled InGaAs photomultiplier was used. In the case of $\mathrm{BaSi}_{2}$-side excitation, the excitation laser light was incident on the $\mathrm{BaSi}_{2}$ layers and PL was detected from the $\mathrm{BaSi}_{2}$ side. In the Si-side excitation, on the other hand, the laser line was introduced from the Si substrate; photoexcited carriers were generated there and were transferred to the $\mathrm{BaSi}_{2} / \mathrm{Si}$ interface because of a long minority carrier diffusion length in Si substrates, and the PL was detected from the BaSi2 side.

\section{Results and discussion}

First, we present the PL spectrum of undoped $\mathrm{BaSi}_{2}$ films (sample A), which were formed with $R_{\mathrm{Ba}} / R_{\mathrm{Si}}=4.0$. This value is far away from the optimum value of 2.2 , wherein the photoresponsivity of $\mathrm{BaSi}_{2}$ films reached a maximum. ${ }^{26}$ Since the absorption coefficient, $\alpha$, exceeds $5 \times 10^{5} \mathrm{~cm}^{-1}$ in $\mathrm{BaSi}_{2}$ at a wavelength of $442 \mathrm{~nm}$ or $532 \mathrm{~nm},{ }^{14}$ the penetration depth of the laser light is estimated to be less than $3 / \alpha \sim 60 \mathrm{~nm}$. Therefore, the photogenerated carriers (electron and holes) recombine within the $\mathrm{BaSi}_{2}$ films in the case of $\mathrm{BaSi}_{2}$-side excitation. Figure 2(a) shows the PL spectrum when the excitation power was $P=240 \mathrm{~mW} / \mathrm{cm}^{2}$, measured at $9 \mathrm{~K}$. As previously reported in Ref. 21, the $\mathrm{BaSi}_{2}$ film in sample $\mathrm{A}$ is defective because its $R_{\mathrm{Ba}} / R_{\mathrm{Si}}$ (4.0) was far away from 2.2. We reproduced well the PL spectrum (black line) by four Gaussian curves (dash-dot lines) as denoted by peaks $1-4$ at $0.86,0.98,1.04$, and $1.12 \mathrm{eV}$, respectively. Their summation is shown by the black dash line. Figure $2(\mathrm{~b})$ shows the PL intensity vs the excitation power $(P)$ for this sample at $9 \mathrm{~K}$. For the low excitation range up to around $P=10 \mathrm{~mW} / \mathrm{cm}^{2}$, the PL intensity increases almost proportionally with $P$. The proportionality factor, $\gamma$, is close to 1 for each spectrum. On the other hand, $\gamma$ becomes much smaller than 1 for the higher excitation range. Based on this result, we attributed the PL to the transition of electrons between localized states within the bandgap. This result can be interpreted as follows. In the low 
excitation range, the number of electrons at higher localized states increases as the excitation power increases, leading to an increase in PL intensity. However, when the excitation becomes much higher, such localized states saturate, and therefore the PL intensity also begins to saturate.

Next, the effect of atomic $H$ supply on the photoresponse and PL spectra of undoped-BaSi2 films grown with $R_{\mathrm{Ba}} / R_{\mathrm{Si}}=2.2^{22}$ is discussed. Figure $3(\mathrm{a})$ shows the photoresponse spectra of samples $\mathrm{B}$ and $\mathrm{C}$ with a bias voltage of $0.3 \mathrm{~V}$. The photoresponsivity of sample $\mathrm{C}$ is higher by a factor of 6 than that of sample $\mathrm{B}$, meaning that the recombination rate in sample $\mathrm{C}$ became smaller by the atomic $\mathrm{H}$ supply than in sample B. We attributed this enhancement of photoresponsivity to the defect levels in sample $\mathrm{C}$ becoming inactived by the $\mathrm{H}$ passivation. Figure 3(b) shows the PL spectra of undoped $\mathrm{BaSi}_{2}$ films (samples $\mathrm{B}$ and $\mathrm{C}$ ) obtained by the $\mathrm{BaSi}_{2}$-side excitation at $8 \mathrm{~K}$. For sample B, grown without the atomic H passivation, we observe a PL peak at around 0.82 $\mathrm{eV}$, which is smaller by approximately $0.5 \mathrm{eV}$ than the band gap of $\mathrm{BaSi}$. This result suggests the presence of deep defect levels in sample B like in sample A. For sample B, we can reproduce the measured PL spectrum by two Gaussian curves, meaning that the number of defect levels decreased from four in sample A to two in sample B. This is because the $\mathrm{BaSi}_{2}$ films in sample $\mathrm{B}$ were grown not at $R_{\mathrm{Ba}} / R_{\mathrm{Si}}=4.0$, but at 2.2 , the optimum value of $R_{\mathrm{Ba}} / R_{\mathrm{Si}}$ when grown at $580{ }^{\circ} \mathrm{C}$. In contrast to sample $\mathrm{B}$, distinct peaks are not observed in the PL spectrum for sample $\mathrm{C}$, passivated with $\mathrm{H}$ for $15 \mathrm{~min}$.

We next move on to B-doped BaSi2 films. Figure 4(a) shows the photoresponse spectra of low- and high B-doped BaSi2 films (samples D and E) at RT. For sample D, low B-doped $\mathrm{BaSi}_{2}$ film, the photoresponsivity became approximately half of undoped ones in sample B. In contrast, the photoresponsivity of sample E, high B-doped $\mathrm{BaSi}_{2}$ films, became much higher than that of sample $\mathrm{D}$. This result suggests that $\mathrm{BaSi}_{2}$ films in sample $\mathrm{E}$ is less defective than undoped $\mathrm{BaSi}_{2}$ films and low B-doped ones. Figure 4(b) shows the $\mathrm{PL}$ spectra of these samples for $\mathrm{BaSi}_{2}$-side excitation at $8 \mathrm{~K}$. For low B-doped $\mathrm{BaSi}_{2}$ films in sample D, the PL intensity was quite small compared to sample E. We therefore suppose that there are lot of non-radiative defects remaining in sample D. Considering that B atoms are expected to fill $\mathrm{V}_{\mathrm{Si}}$ in $\mathrm{BaSi}_{2}$ films, when we add more $\mathrm{B}$ atoms in $\mathrm{BaSi}_{2}$ films in sample $\mathrm{E}$, more $\mathrm{V}_{\mathrm{Si}}$ can be passivated, and thus there are less localized states. We think that this is the reason why the PL intensity and photoresponsivity are higher in sample E than in samples B and D.

We next discuss the effect of atomic $\mathrm{H}$ supply on the photoresponse and PL spectra 
of low B-doped BaSi2 films (samples F, G, and H). The atomic hydrogen supply duration $\left(t_{\mathrm{H}}\right)$ was $0,5,15 \mathrm{~min}$, respectively. Sample $\mathrm{F}$ is identical to sample D. We formed sample F to confirm the reproducibility of optical properties obtained for sample D. Figure 5(a) shows the photoresponse spectra of these samples. The photoresponsivity of sample $\mathrm{F}\left(t_{\mathrm{H}}=\right.$ $0 \mathrm{~min}$ ) was quite small, but increased drastically at $t_{\mathrm{H}}=5 \mathrm{~min}$ in sample $\mathrm{G}$, much higher than those of sample $\mathrm{C}$, H-passivated undoped $\mathrm{BaSi}_{2}$ films in Fig. 2, and sample $\mathrm{E}$, high B-doped $\mathrm{BaSi}_{2}$ films in Fig. 4. This result suggests that the defects in B-doped $\mathrm{BaSi}_{2}$ films are also inactivated by atomic $\mathrm{H}$ like in $\mathrm{H}$-passivated undoped $\mathrm{BaSi}_{2}$ films. For further increase in $t_{\mathrm{H}}$, however, the photoresponsivity decreased, suggesting the formation of defect levels within the band gap. Figure 5(b) shows the PL spectra of samples F-H for $\mathrm{BaSi}_{2}$-side excitation at $8 \mathrm{~K}$, which are reproducible by two Gaussian curves for samples $\mathrm{G}$ and $\mathrm{H}$. The result is in agreement with the photoresponse spectra: the PL was very low for sample $\mathrm{F}\left(t_{\mathrm{H}}=0 \mathrm{~min}\right)$. For sample $\mathrm{G}$ passivated with $\mathrm{H}$ during $5 \mathrm{~min}$, the PL intensity was the highest among the three samples, indicating that defects were passivated. In sample $\mathrm{H}$ $\left(t_{\mathrm{H}}=15 \mathrm{~min}\right)$, however, the PL intensity decreased, and we can see that the contribution of deep defect levels at around $0.9 \mathrm{eV}$ becomes high. The presence of such deep levels has an impact on the photoresponsitiy from the viewpoint of the Shockley-Read-Hall recombination model. ${ }^{37}$ To confirm the effect of atomic $\mathrm{H}$ on the PL of low B-doped $\mathrm{BaSi}_{2}$ films, we also measured PL spectra of samples grown on high- $\rho \operatorname{Si}(111)$ substrates in samples I-J. According to our previous work ${ }^{24,38}$, when low- $\rho$ Si substrates are used, it is difficult to prevent step bunching on the $\mathrm{Si}(111)$ surface after we perform thermal cleaning at $900{ }^{\circ} \mathrm{C}$ to remove the protective oxide layer on the Si surface, causing the generation of defects around the $\mathrm{BaSi}_{2} / \mathrm{Si}$ interface. Thus, there is a possibility that such defects are responsible for deep levels observed in the PL spectra of samples A-H. Such defects can be avoided in samples I-K because they were grown on high- $\rho \operatorname{Si}(111)$ substrates. Figures 6(a) and $6(\mathrm{~b})$ show the PL spectra of these samples at $8 \mathrm{~K}$ obtained for $\mathrm{BaSi}_{2}$-side and Si-side excitations, respectively. Figure 6(c) shows the band alignment of the $\mathrm{BaSi}_{2} / \mathrm{Si}$ heterostructure. Because of the small electron affinity of $\mathrm{BaSi}_{2}(3.2 \mathrm{eV}),{ }^{39}$ large conduction band and valence band offsets exist at the heterointerface. This means that the transfer of holes generated in $\mathrm{BaSi}_{2}$ into $\mathrm{Si}$ by the $\mathrm{BaSi}_{2}$-side excitation are blocked by a large valence band discontinuity, $\Delta E \mathrm{v}$, at the heterointerface. The minority-carrier diffusion length is so large in high- $\rho$ Si substrates, photogenerated electron and holes by the Si-side excitation diffuse into the $\mathrm{BaSi}_{2} / \mathrm{Si}$ interface and recombine there. Figures 6(a) shows that samples $\mathrm{J}$ and $\mathrm{K}$ exhibit PL spectra similar to those of samples G and H in Fig. 5(b), implying that 
the effect of defects around the $\mathrm{BaSi}_{2} / \mathrm{Si}$ interface on the PL spectra of these samples is negligible. For the Si-side excitation measurement shown in Fig. 6(b), we can observe a sharp peak at $1.09 \mathrm{eV}$, related to the $\mathrm{Si}$ substrate. It is interesting to note that its intensity is also sensitive to $t_{\mathrm{H}}$, meaning that the atomic $\mathrm{H}$ supply influences the optical properties of the $\mathrm{BaSi}_{2} / \mathrm{Si}$ interface. At present, we do not have much information to discuss further on this matter. However, we can at least state that the supply of atomic $\mathrm{H}$ is also a very effective means to enhance the photoresponsivity of $\mathrm{B}$-doped $\mathrm{BaSi}_{2}$ films.

\section{Conclusions}

We fabricated 0.5 - $\mu$ m-thick undoped $\mathrm{BaSi}_{2}$ epitaxial films on $\mathrm{Si}(111)$ substrates by $\mathrm{MBE}$, and investigated the effect of doping $\mathrm{B}$ and/or atomic $\mathrm{H}$ on the photoresponse and photoluminescence spectra of the $\mathrm{BaSi}_{2}$ films. The enhancement of photoresponsivity was observed by doping of B atoms $\left(p=2 \times 10^{18} \mathrm{~cm}^{-3}\right)$. The photoresponsivity of low B-doped $\mathrm{BaSi}_{2}$ films was significantly enhanced by atomic $\mathrm{H}$ supply for $5 \mathrm{~min}$. Much further atomic $\mathrm{H}$ supply (15 min), however, decreased the photoresponsivity of $\mathrm{BaSi}_{2}$ films. PL measurements at 8-9 K highlighted the existence of localized states within the bandgap. Measured PL spectra were reproduced by using two or four Gaussian curves. By comparing the PL spectra between samples with small and high photoresponsivities, it was found that the contribution of PL at around 0.8-0.9 eV corresponding to deep defect levels was smaller for samples exhibiting higher photoresponsitvity than those with small photoresponsivity. We therefore conclude that the enhancement of photoresponsivity was ascribed to the decrease of deep defect levels by atomic $\mathrm{H}$ and/or $\mathrm{B}$ atoms, which might fill $\mathrm{V}_{\mathrm{Si}}$ in $\mathrm{BaSi}_{2}$ films.

\section{Acknowledgments}

This work was financially supported by a JSPS KAKENHI (18H03767). 


\section{References}

${ }^{1}$ J. Evers, G. Oeh-ger, and A. Weiss, Angew. Chem. Int. Ed. Engl. 16, 659 (1977).

${ }^{2}$ M. Imai and T. Hirano, J. Alloys. Compd. 224, 111 (1995).

${ }^{3}$ R. A. McKee, F. J. Walker, J. R. Conner, and R. Raj, Appl. Phys. Lett. 63, 2818 (1993).

${ }^{4}$ K. Toh, K. O. Hara, N. Usami, N. Saito, N. Yoshizawa, K. Toko, and T. Suemasu, Jpn. J. Appl. Phys. 51, 095501 (2012).

${ }^{5}$ R. Takabe, K. Nakamura, M. Baba, W. Du, M. A. Khan, K. Toko, M. Sasase, K. O. Hara, N. Usami, and T. Suemasu, Jpn. J. Appl. Phys. 53, 04ER04 (2014).

${ }^{6}$ T. Suemasu and N. Usami, J. Phys. D: Appl. Phys. 50, 023001 (2017).

${ }^{7}$ K. Toh, T. Saito, and T. Suemasu, Jpn. J. Appl. Phys. 50, 068001 (2011).

${ }^{8}$ D. B. Migas, V. L. Shaposhnikov, and V. E. Borisenko, Phys. Status Solidi B 244, 2611 (2007).

${ }^{9}$ M. Kumar, N. Umezawa, and M. Imai, J. Appl. Phys. 115, 203718 (2014).

${ }^{10}$ M. Kumar, N. Umezawa, and M. Imai, Appl. Phys. Express 7, 071203 (2014).

${ }^{11}$ K. O. Hara, N. Usami, K. Nakamura, R. Takabe, M. Baba, K. Toko, and T.

Suemasu, Appl. Phys. Express 6, 112302 (2013).

${ }^{12}$ M. Baba, K. Toh, K. Toko, N. Saito, N. Yoshizawa, K. Jiptner, T. Sakiguchi, K. O. Hara, N. Usami, and T. Suemasu, J. Cryst. Growth 348, 75 (2012).

${ }^{13}$ M. Baba, S. Tsurekawa, K. Watanabe, W. Du, K. Toko, K. O. Hara, N. Usami, T.

Sekiguchi, and T. Suemasu, Appl. Phys. Lett. 103, 142113 (2013).

${ }^{14}$ M. Baba, M. Kohyama, and T. Suemasu, J. Appl. Phys. 120, 085311 (2016).

${ }^{15}$ R. Takabe, H. Takeuchi, W. Du, K. Ito, K. Toko, S. Ueda, A. Kimura, and T. Suemasu, J. Appl. Phys. 119, 165304 (2016).

${ }^{16}$ R. Takabe, S. Yachi, W. Du, D. Tsukahara, H. Takeuchi, K. Toko, and T. Suemasu, AIP Adv. 6, 085107 (2016).

${ }^{17}$ D. Tsukahara, S. Yachi, H. Takeuchi, R. Takabe, W. Du, M. Baba, Y. Li, K. Toko, N. Usami, and T. Suemasu, Appl. Phys. Lett. 108, 152101 (2016).

${ }^{18}$ S. Yachi, R. Takabe, K. Toko, and T. Suemasu, Appl. Phys. Lett. 109, 072103 (2016).

${ }^{19}$ T. Deng, T. Sato, Z. Xu, R. Takabe, S. Yachi, Y. Yamashita, K. Toko, and T. Suemasu, Appl. Phys. Express 11, 062301 (2018).

${ }^{20}$ K. Kodama, Y. Yamashita, K. Toko, and T. Suemasu, Appl. Phys. Express 12, 041005 (2019).

${ }^{21}$ L. Benincasa, H. Hoshida, T. Deng, T. Sato, Z. Xu, K. Toko, Y. Terai, and T. Sueamsu, J. Phys. Commun. 3, 075005 (2019).

${ }^{22}$ T. Sato, Y. Yamashita, Z. Xu, K. Toko, S. Gambarelli, M. Imai, and T. Suemasu, Appl. Phys. Express 12, 111001 (2019).

${ }^{23}$ H. Takeuchi, W. Du, M. Baba, R. Takabe, K. Toko, and T. Suemasu, Jpn. J. Appl. Phys. 54, 07JE01 (2015).

${ }^{24}$ Y. Yamashita, T. Sato, K. Toko, and T. Suemasu, Jpn. J. Appl. Phys. 57, 075801(2018).

${ }^{25}$ T. Sato, C. Lombard, Y. Yamashita, Z. Xu, L. Benincasa, K. Toko, S. Gambarelli, and T. Suemasu, Appl. Phys. Express 12, 061005 (2019).

${ }^{26}$ R. Takabe, T. Deng, K. Kodama, Y. Yamashita, T. Sato, K. Toko, and T. Suemasu, J. Appl. Phys. 123, 045703 (2018). 
${ }^{27}$ M. Kumar, N. Umezawa, W. Zou, and M. Imai, J. Mater. Chem. A 5, 25293 (2017).

${ }^{28}$ Z. Xu, K. Gotoh, T. Deng, T. Sato, R. Takabe, K. Toko, N. Usami, and T. Suemasu, AIP Advances 8, 055306 (2018).

${ }^{29}$ Z. Xu, D. A. Shohonov, A. B. Filonov, K. Gotoh, T. Deng, S. Honda, K. Toko, N. Usami, D. B. Migas, V. E. Borisenko, and T. Suemasu, Phys. Rev. Mater. 3, 065403 (2019).

${ }^{30}$ M. A. Khan, K. O. Hara, W. Du, M. Baba, K. Nakamura, M. Suzuno, K. Toko, N. Usami, and T. Suemasu, Appl. Phys. Lett. 102, 112107 (2013).

${ }^{31}$ M. A. Khan, K. Nakamura, W. Du, K. Toko, N. Usami, and T. Suemasu, Appl. Phys. Lett. 104, 252104 (2014).

${ }^{32}$ S. M. Sze, Physics of Semiconductor Devices, 2nd ed. (Wiley, New York, 1981).

${ }^{33}$ M. Tajima, J. Cryst. Growth 103, 1 (1990).

${ }^{34}$ E. C. Lightowlers and V. Higgs, Phys. Status Solidi a 138, 665 (1993).

${ }^{35}$ M. Tajima, Y. Iwata, F. Okayama, H. Toyota, H. Onodera, and T. Sekiguchi, J. Appl. Phys. 111, 113523 (2012).

${ }^{36}$ T. Deng, T. Suemasu, D. A. Shobonov, I. S. Samusevich, A. B. Filonov, D. B. Migas, and V. E. Borisenko, Thin Solid Films 661, 7 (2018).

${ }^{37}$ W. Schockley and W. T. Read, Phys. Rev. 87, 835 (1952).

${ }^{38}$ Y. Yamashita, S. Yachi, R. Takabe, T. Sato, M. E. Bayu, K. Toko, and T. Suemasu, Jpn. J. Appl. Phys. 57, 025501 (2018).

${ }^{39}$ T. Suemasu, K. Morita, M. Kobayashi, M. Saida, and M. Sasaki, Jpn. J. Appl. Phys. 45, L519 (2006). 


\section{Figure Captions}

Fig. 1. Crystal structure of $\mathrm{BaSi}_{2}$. Three inequivalent $\mathrm{Si}$ atoms and two inequivalent $\mathrm{Ba}$ atoms consist of the lattice of $\mathrm{BaSi}_{2}$.

Fig. 2. (a) PL spectrum of undoped $\mathrm{BaSi}_{2}$ films (sample $\mathrm{A}$ ) at $9 \mathrm{~K}$ excited from the $\mathrm{BaSi}_{2}$-side. The measured PL spectrum (black line) is reproduced well by four Gaussian curves (dash-dot lines) peaking at Peaks 1-4. (b) Excitation power dependence of PL intensity for each peak at $9 \mathrm{~K} .{ }^{21}$

Fig. 3. (a) Photoresponse spectra of undoped $\mathrm{BaSi}_{2}$ films (samples $\mathrm{B}$ and $\mathrm{C}$ ) at $\mathrm{RT}$. $t_{\mathrm{H}}$ is 0 and $15 \mathrm{~min}$, respectively. (b) PL spectra of these samples for $\mathrm{BaSi}_{2}$-side excitation at $8 \mathrm{~K}$. The PL spectrum of sample B is reproduced by two Gaussian curves.

Fig. 4. (b) Photoresponse spectra of B-doped $\mathrm{BaSi}_{2}$ films (samples $\mathrm{D}$ and $\mathrm{E}$ ), corresponding to "Low" and "High" B-doped BaSi2 films, respectively at RT. (a) PL spectra of these samples for $\mathrm{BaSi}_{2}$-side excitation at $8 \mathrm{~K}$. The PL spectrum of sample $\mathrm{E}$ is reproducible by two Gaussian curves.

Fig. 5. (a) Photoresponse spectra of low B-doped BaSi2 films (samples F, G and H) at RT. $t_{\mathrm{H}}$ is 0 , 5, and $15 \mathrm{~min}$, respectively. (b) PL spectra of these samples for $\mathrm{BaSi}_{2}$-side excitation at $8 \mathrm{~K}$. The PL spectra of samples $\mathrm{G}$ and $\mathrm{H}$ are reproducible by two Gaussian curves.

Fig. 6. (a) PL spectra of low B-doped BaSi2 films (samples I, J, and K) obtained by the $\mathrm{BaSi}_{2}$-side excitation at $8 \mathrm{~K} . t_{\mathrm{H}}$ is 0,5 , and $15 \mathrm{~min}$, respectively. The PL spectra of samples $\mathrm{J}$ and $\mathrm{K}$ are reproducible by two Gaussian curves. (b) PL spectra of these samples excited from the $\mathrm{Si}$ side at $8 \mathrm{~K}$. (c) Energy band alignment of $\mathrm{BaSi}_{2}$ and $\mathrm{Si}$ with respect to the vacuum level. 
TABLE I. Sample preparation: $\mathrm{BaSi}_{2}$ layer thickness $(d), R_{\mathrm{Ba}} / R_{\mathrm{Si}}$, B-doped concentration, atomic hydrogen supply duration $\left(t_{\mathrm{H}}\right)$ and $\mathrm{Si}$ substrate resistivity $(\rho)$. The hole concentration of "Low" and "High" B-doped BaSi2 films is approximately $1 \times 10^{16}$ and $2 \times$ $10^{18} \mathrm{~cm}^{-3}$, respectively, at RT.

\begin{tabular}{cccccc}
\hline Sample & $\mathrm{d}$ & $R_{\mathrm{Ba}} / R_{\mathrm{Si}}$ & B-doped & $t_{\mathrm{H}}$ & $\rho$ \\
& $(\mu \mathrm{m})$ & & concentration & $(\mathrm{min})$ & $(\Omega \mathrm{cm})$ \\
\hline $\mathrm{A}$ & 0.5 & 4.0 & Undoped & 0 & 0.01 \\
\hline $\mathrm{B}$ & 0.5 & 2.0 & Undoped & 0 & 0.01 \\
\hline $\mathrm{C}$ & 0.5 & 2.0 & Undoped & 15 & 0.01 \\
$\mathrm{D}$ & 0.5 & 2.0 & Low & 0 & 0.01 \\
$\mathrm{E}$ & 0.5 & 2.0 & High & 0 & 0.01 \\
$\mathrm{~F}$ & 0.5 & 2.0 & Low & 0 & 0.01 \\
$\mathrm{G}$ & 0.5 & 2.0 & Low & 5 & 0.01 \\
$\mathrm{H}$ & 0.5 & 2.0 & Low & 15 & 0.01 \\
$\mathrm{I}$ & 0.5 & 2.0 & Low & 0 & $>1000$ \\
$\mathrm{~J}$ & 0.5 & 2.0 & Low & 5 & $>1000$ \\
$\mathrm{~K}$ & 0.5 & 2.0 & Low & 15 & $>1000$ \\
\hline & & & & & \\
\hline
\end{tabular}




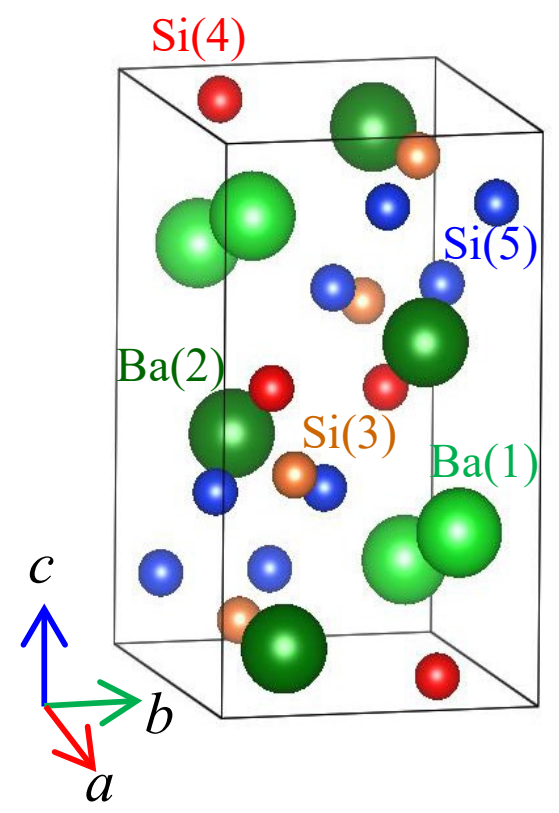

Fig. 1 

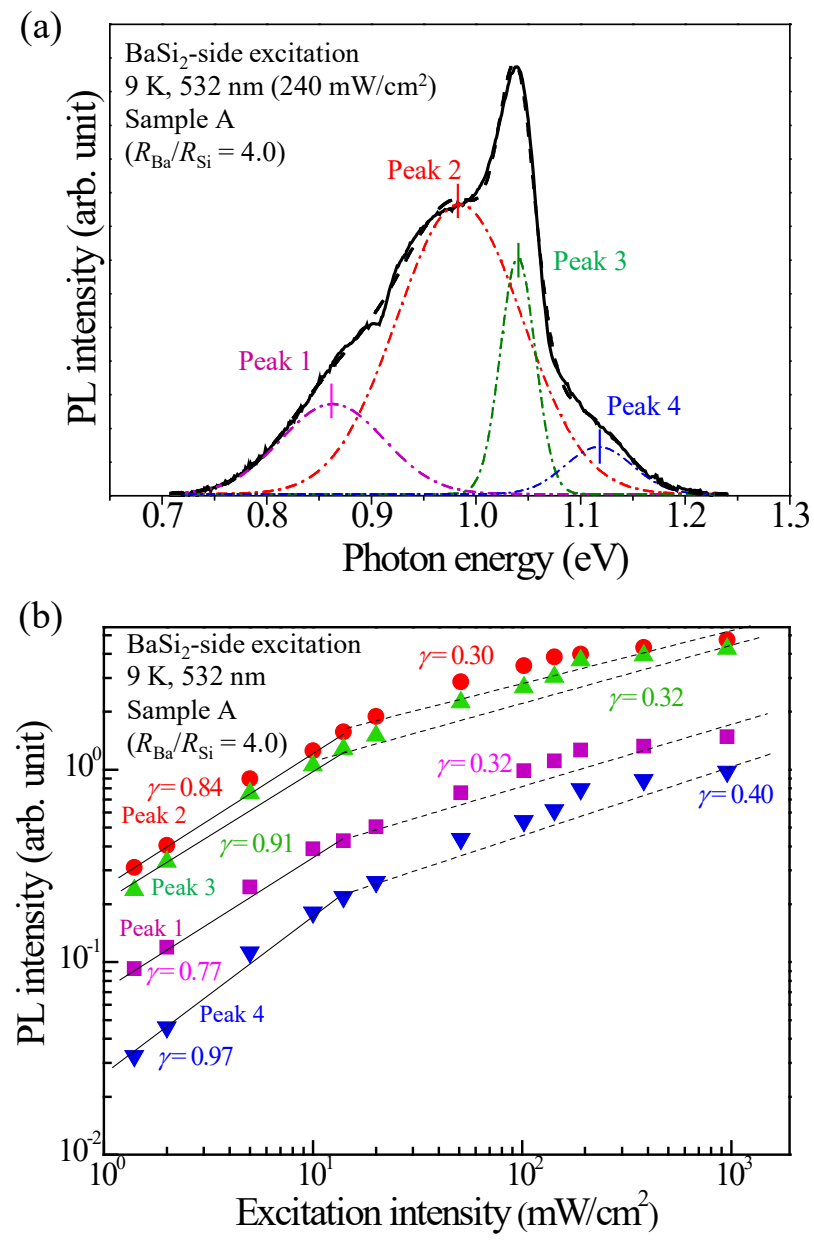

Fig. 2 

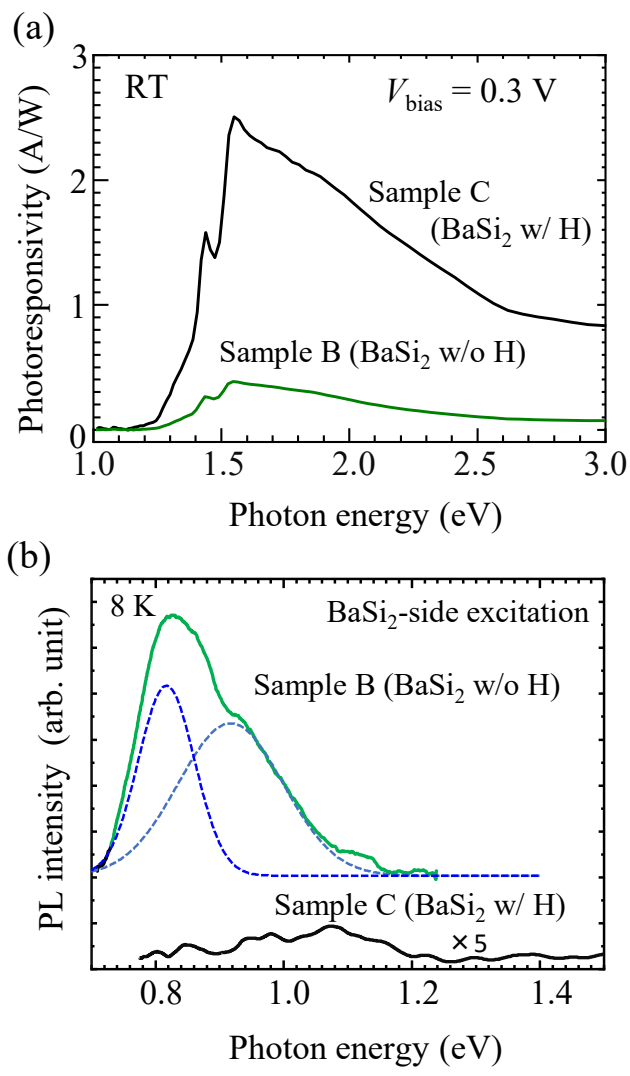

Fig. 3 
(a)
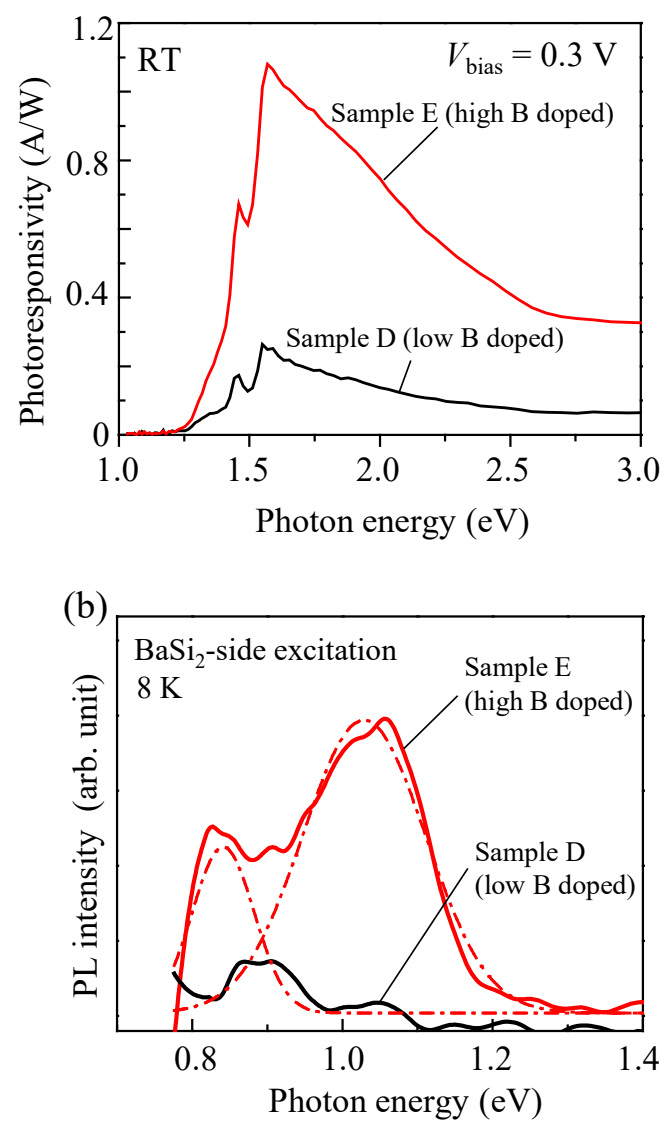

Fig. 4 

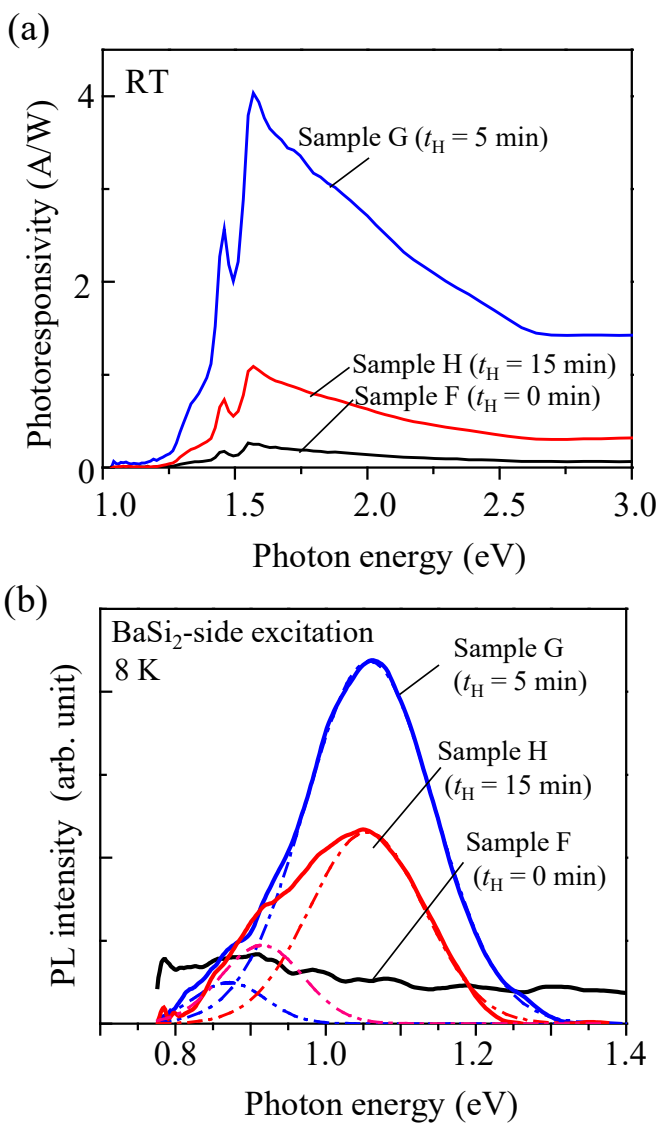

Fig. 5 

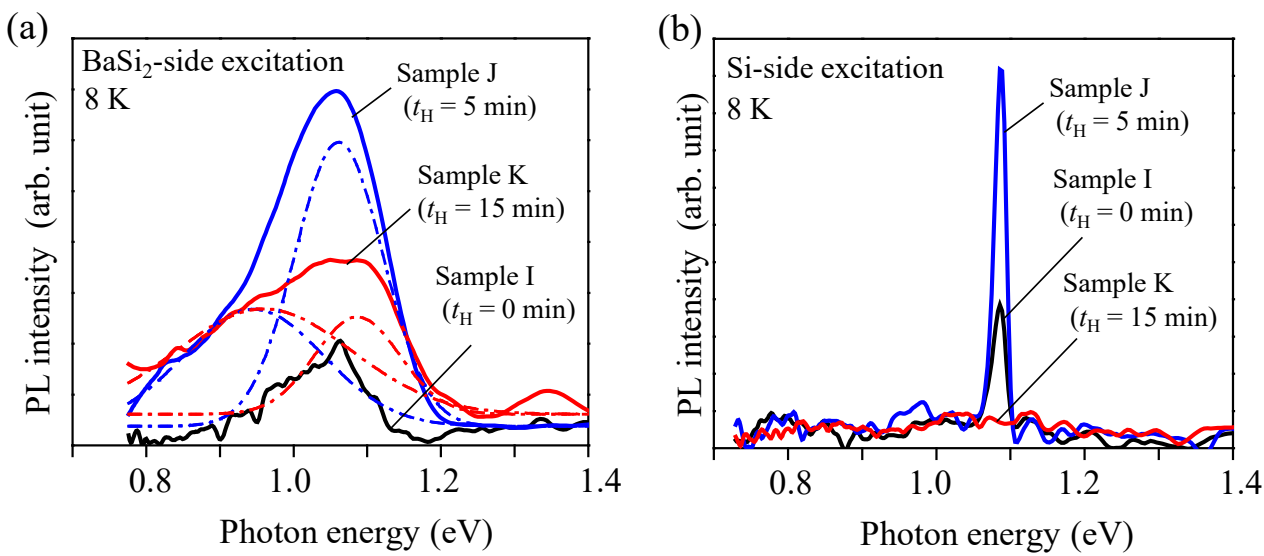

(c)

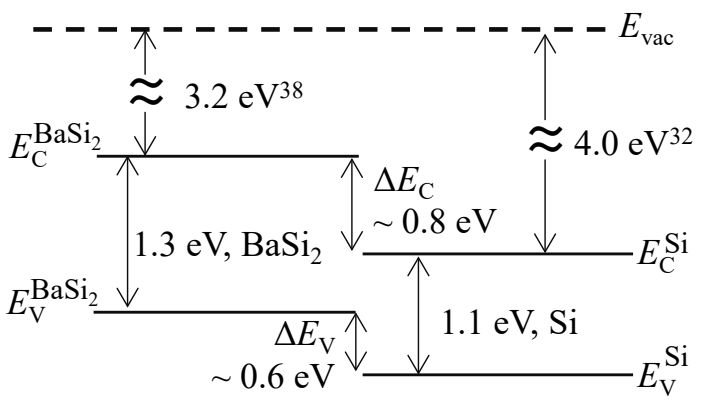

Fig. 6 